\title{
Vitamin D intoxication caused by ingestion of commercial cat food in three kittens
}

15(8) 730-736

(C) ISFM and AAFP 2013

Reprints and permissions:

sagepub.co.uk/journalsPermissions.nav DOI: $10.1177 / 1098612 \times 12472180$ jfms.com

(S)AGE

\author{
Astrid Wehner ${ }^{1}$, Julia Katzenberger ${ }^{1}$, Anna Groth ${ }^{2}$, \\ Roswitha Dorsch ${ }^{1}$, Petra Koelle ${ }^{1}$, Katrin Hartmann ${ }^{1}$ \\ and Karin Weber ${ }^{1}$
}

\begin{abstract}
Two siblings, a 6-month-old sexually intact male weighing $2.5 \mathrm{~kg}$ (cat 1) and a sexually intact female (cat 2) British Shorthair cat weighing $2.3 \mathrm{~kg}$, were examined because of a 3-week history of polyuria, lethargy and laboured breathing. One year previously, another sibling (cat 3) had been presented because of similar, yet more severe, clinical signs at the age of 5 months. Physical examination revealed lethargy, dehydration and polypnoea with slightly increased inspiratory effort. Diagnostic investigation revealed severe hypercalcaemia (cats 1-3), renal azotaemia (cats 1 and 3 ) and a radiologically generalised miliary interstitial pattern of the lungs (cats 1-3) attributable to hypervitaminosis D caused by ingestion of commercial cat food. Cat 3 was euthanased. Cats 1 and 2 were treated with isotonic saline solution (180 ml/kg IV daily), sucralfate (30 mg/kg PO q12h), terbutaline (only cat $1: 0.1 \mathrm{mg} / \mathrm{kg}$ SC q4h), furosemide (1.5 mg/kg IV q8h) and tapering doses of prednisolone. Cat 2 was normal on day 14. Cat 1 had stable renal disease and was followed up to day 672. The radiological generalised military interstitial pattern of the lungs had improved markedly. Excessive cholecalciferol-containing commercially available cat food poses a great hazard to cats. Supportive treatment may result in long-term survival and improvement of radiological pulmonary abnormalities.
\end{abstract}

Accepted: 29 November 2012

Hypervitaminosis $\mathrm{D}$ in cats has been reported from ingestion of vitamin $\mathrm{D}_{3}$-containing rodenticide and pet food. Affected animals present with lethargy, chronic weight loss, anorexia, polyuria, episodic vomiting and signs of respiratory disturbance, such as cough and difficulty in breathing. Laboratory changes in cats with hypervitaminosis D included hypercalcaemia, hyperphosphataemia, alkalosis, high urea and creatinine concentrations, hypercalciuria and a decrease in urine concentrating ability. ${ }^{1-4}$

\section{Case descriptions}

A 6-month-old sexually intact male British Shorthair cat (cat 1) weighing $2.5 \mathrm{~kg}$ presented to the Veterinary Teaching Hospital of the Ludwig Maximilian University of Munich for a 3-week history of polyuria, lethargy and laboured breathing breathing. The cat's littermate $(2.3 \mathrm{~kg}$ sexuallyintact female - cat 2) also living in their household, showed similar, but less severe, signs. One year previously, a sibling of the two cats (cat 3) (same parents, but from a previous litter) had been presented by the same owners because of similar, yet more severe, clinical signs (polyuria, polydipsia, lethargy, anorexia, coughing for 3 months) at the age of 5 months. This cat had been euthanased owing to his overall bad condition, poor prognosis and financial constraints after the initial diagnostic evaluation had revealed renal failure with marked renal azotaemia, metabolic acidosis, hyperphosphataemia, marked anaemia and severe hypercalcaemia, as well as severe radiographic lung changes characterised by a generalised bronchointerstitial pattern and peribronchial cuffing.

On physical examination cat 1 was lethargic and moderately dehydrated. It showed polypnoea with

\footnotetext{
${ }^{1}$ Ludwig Maximilian University, Clinic of Small Animal Medicine, Munich, Germany

${ }^{2}$ North Downs Specialist Referrals, Bletchingley, UK
}

\section{Corresponding author:}

Astrid Wehner Dr med vet, Diplomate ECVIM-CA, Ludwig Maximilian University, Veterinaerstrasse 13, Munich, 80804, Germany

Email: a.wehner@medizinische-kleintierklinik.de 
Table 1 Results of laboratory analysis of cat 1

\begin{tabular}{|c|c|c|c|c|c|c|c|c|}
\hline & Day 1 & Day 2 & Day 14 & Day 21 & Day 42 & Day 77 & Day 672 & Reference interval \\
\hline Creatinine $(\mu \mathrm{mol} / \mathrm{l})$ & 363 & & 388 & 453 & 453 & 295 & 346 & $0-168$ \\
\hline BUN (mmol/l) & 36.1 & & 27.7 & 36 & 27.4 & 28.2 & 20.76 & $5.0-11.3$ \\
\hline $\begin{array}{l}\text { Ionised calcium } \\
(\mathrm{mmol} / \mathrm{l})\end{array}$ & 2.02 & 2.3 & 1.36 & 1.33 & 1.35 & 1.35 & 1.35 & $1.20-1.35$ \\
\hline Phosphate (mmol/l) & 2.7 & & 2.7 & & & 2.63 & 1.76 & $0.97-2.36$ \\
\hline PTH (pg/ml) & 7 & & & & & & & $3-24$ \\
\hline PTHrp (pmol/l) & 0.5 & & & & & & & $<0.8$ \\
\hline $25(\mathrm{OH}) \mathrm{D}_{3}(\mathrm{nmol} / \mathrm{l})$ & 240.9 & & & & & 63 & & 48-192 \\
\hline $1,25(\mathrm{OH})_{2} \mathrm{D}_{3}(\mathrm{pg} / \mathrm{ml})$ & 400 & & & & & 125 & & $<20(30)$ \\
\hline
\end{tabular}

BUN = blood urea nitrogen; $\mathrm{PTH}=$ parathyroid hormone; PTHrp = parathyroid hormone related protein

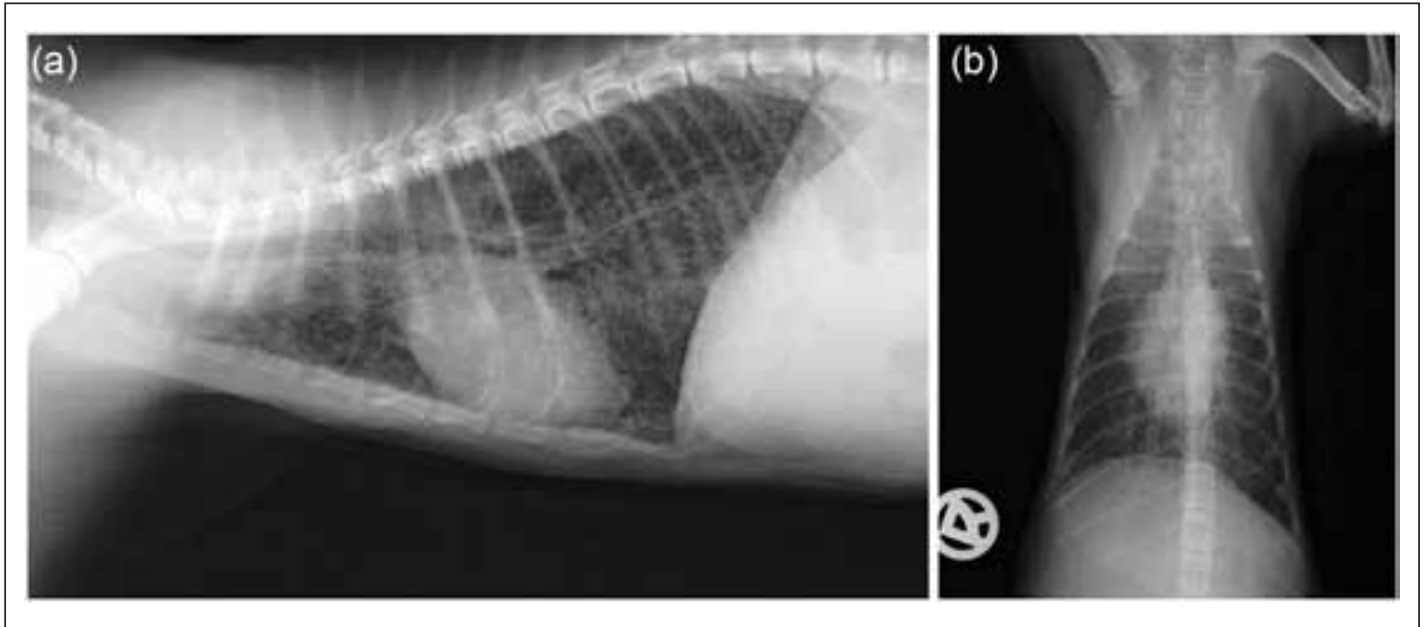

Figure 1 Thorax, right lateral (a) and dorsoventral (b) view of cat 1 at presentation. The lungs were well inflated and the diaphragm flattened, which may represent dyspnoea. There was evidence of a generalised miliary interstitial pattern and peribronchial cuffing throughout the lungs, and a curvilinear, interrupted, mineral opacity line superimposed on the cardiac silhouette in the area of the ascending aorta and the left ventricular outflow tract, as well as evidence of bronchial mineralisation. Differential diagnosis for the generalised interstitial pattern included interstitial mineralisation secondary to hypercalcaemia, bronchopneumonia and, less likely, neoplasia secondary to a round cell tumour. Fungal pneumonia, metastatic neoplasia or uraemic pneumonitis were considered unlikely

slightly increased inspiratory effort; its rectal temperature was slightly below the reference interval $\left(37.4^{\circ} \mathrm{C}\right)$. On palpation, the size of the kidneys seemed to be within the normal range for an adult cat. ${ }^{5}$ Other physical examination findings were unremarkable.

Initial diagnostic work-up included a complete blood count, serum biochemistry, venous blood gas analysis, urinalysis (including culture), thoracic radiographs, and abdominal ultrasound.

Abnormal serum biochemical findings are summarised (Table 1). Blood gas analysis revealed mixed acidosis $(\mathrm{pH}$ 7.18, reference interval 7.34-7.44). On urinalysis, a decreased urine specific gravity of $1.016,1+$ protein, $3+$ glucose, $2-8$ leukocytes/high power field (hpf) and 2 granular casts / hpf were identified. Urine culture was negative. Thoracic radiographs showed evidence of a generalised miliary interstitial pattern and peribronchial cuffing throughout the lungs, as well as evidence of bronchial mineralisation (Figure 1). Abdominal ultrasound showed borderline large kidneys (length: right kidney, $4.2 \mathrm{~cm}$; left kidney, $4.3 \mathrm{~cm}$ ) with a hyperechoic cortex and a broad medullary rim sign. The other organs were unremarkable.

The cat was hospitalised for further diagnostic workup and supportive treatment. After 4 days the sibling, cat 2, was presented. Apart from intermittent slightly labored breathing, physical examination findings were unremarkable. Serum biochemistry also revealed hypercalcaemia (Table 2). The rest of the serum parameters, as well as the CBC, showed no abnormalities. The urine had a specific gravity of 1.014 and contained $1+$ protein.

Results of thoracic radiographs and abdominal ultrasound of cat 2 were similar to the findings for cat 1 .

Further work-up was focused on possible differential diagnosis for hypercalcaemia. Blood samples were 
Table 2 Results of laboratory analysis of cat 2

\begin{tabular}{|c|c|c|c|c|c|c|c|c|}
\hline & Day 1 & Day 2 & Day 14 & Day 21 & Day 42 & Day 77 & Day 672 & Reference interval \\
\hline Creatinine $(\mu \mathrm{mol} / \mathrm{l})$ & 112 & & 102 & 102 & & & & $0-168$ \\
\hline BUN (mmol/l) & 11 & & 15.1 & 14.3 & & & & $5.0-11.3$ \\
\hline $\begin{array}{l}\text { lonised calcium } \\
(\mathrm{mmol} / \mathrm{l})\end{array}$ & 1.98 & 1.91 & 1.31 & 1.29 & 1.27 & 1.25 & & $1.20-1.35$ \\
\hline Phosphate (mmol/l) & 2.16 & & & & & 1.98 & & $0.97-2.36$ \\
\hline PTH $(\mathrm{pg} / \mathrm{ml})$ & 3 & & & & & & & $3-24$ \\
\hline PTHrp (pmol/l) & & & & & & & & $<0.8$ \\
\hline $25(\mathrm{OH}) \mathrm{D}_{3}(\mathrm{nmol} / \mathrm{l})$ & 218.9 & & & & & & & 48-192 \\
\hline $1,25(\mathrm{OH})_{2} \mathrm{D}_{3}(\mathrm{pg} / \mathrm{ml})$ & 266 & & & & & & & $<20(30)$ \\
\hline
\end{tabular}

BUN = blood urea nitrogen; PTH = parathyroid hormone; PTHrp = parathyroid hormone related protein

submitted for measurement of parathyroid hormone (PTH), parathyroid hormone related hormone PTHrp, calcidiol (25-hydroxyvitamin $\left.\mathrm{D}_{3}, 25(\mathrm{OH}) \mathrm{D}_{3}\right)$ and calcitriol (1,25-dihydroxyvitamin $\mathrm{D}_{3}, 1,25(\mathrm{OH})_{2} \mathrm{D}_{3}$; Vet-MedLabor, Idexx Laboratories).

Treatment of both cats was initiated with potassiumsupplemented (ad $20 \mathrm{mmol} / \mathrm{l}$ ) isotonic saline solution (180 ml/kg IV daily) (0.9\% sodium chloride; B Braun), sucralfate (30 mg/kg PO q12h: Ulcogant; Merck) and terbutaline (only cat 1: $0.1 \mathrm{mg} / \mathrm{kg}$ SC q4h; Bricanyl, AstraZeneca). Furosemide (1.5 mg/kg IV q8h) (Dimazon; Intervet) was started after rehydration was achieved. One day after treatment initiation, ionized blood calcium had increased in cat 1 and only slightly decreased in cat 2 (Tables 1 and 2).

Further work-up included in-house snap tests for feline leukaemia virus and feline immunodeficiency virus, as well as immunofluorescence assay for the detection of Toxoplasma gondii antibodies to exclude an underlying infectious cause of the pulmonary changes. Results were negative in both cats. Thereafter, prednisolone (2 $\mathrm{mg} / \mathrm{kg}$ PO q24h: Prednisolone; CP-Pharma) was added to the cats' current medication to enhance calciuresis.

Results of the PTH measurement were in the lower reference interval in both cats. PTHrp was low (only measured in cat 1). Assessment of the vitamin D status revealed a markedly elevated $1.25(\mathrm{OH})_{2} \mathrm{D}_{3}$ in both cats, as well as an elevated $25(\mathrm{OH}) \mathrm{D}_{3}$, consistent with hypervitaminosis $\mathrm{D}$ (Tables 1 and 2).

Thorough questioning of the owner about any vitamin D-containing products in their household revealed no potential source for the vitamin D intoxication. A detailed feeding anamnesis was taken, which showed that all three cats had exclusively been fed commercial cat food (the same two different brands). All three cats had mainly received wet food of one single brand (food 1: about $80 \%$ of their daily food ration) and, to a lesser extent, dry food (food 2) of another brand. Therefore, samples of both diets were sent to a special laboratory for analysis of the cholecalciferol (vitamin $\mathrm{D}_{3}$ ) content by high-performance liquid chromatography (LUFA-ITL
$\mathrm{GmbH}$, Agrolab Laborgruppe, Kiel, Germany). A second sample of food 1 was submitted for measurement of its calcium and phosphate content (Department of Nutrition and Dietetics, Ludwig Maximilian University Munich, Germany) (Table 3).

A diagnosis of vitamin $\mathrm{D}$ intoxication with soft-tissue calcification of the lungs and nephropathy caused by ingestion of commercial cat food was established for the kittens (cats 1 and 2). The same diagnosis was made presumptively for cat 3 as clinical signs, food brands and feeding habits were identical in all three cats. However, PTH, PTHrp, $25(\mathrm{OH}) \mathrm{D}_{3}, 1,25(\mathrm{OH})_{2} \mathrm{D}_{3}$ and vitamin $\mathrm{D}_{3}$ content in the food fed were not measured in cat 3 .

After a hospitalisation period of 5 and 7 days, respectively, the two kittens (cats 1 and 2) improved markedly and were discharged on isotonic saline solution (50 ml/ $\mathrm{kg} \mathrm{SC} \mathrm{q12h),} \mathrm{furosemide} \mathrm{(1.5} \mathrm{mg/kg} \mathrm{PO} \mathrm{q8h),} \mathrm{sucralfate}$ (30 mg/kg PO q8h) and prednisolone (2 mg/kg PO $\mathrm{q} 24 \mathrm{~h})$. In the following weeks, those medications were slowly tapered down, taking the clinical and laboratory findings into account. The owners were advised to feed cooked minced meat, owing to its low calcium content, in combination with a phosphate binder (sucralfate). As soon as the blood calcium had decreased, both cats were switched to a commercial renal diet (food 3).

Follow-up examinations were performed 2, 3, 6, 11 and 96 weeks after discharge. After a gradual, but slow, decline of the blood ionised calcium during hospitalisation (Tables 1 and 2), it had normalised in both cats after 2 weeks. At that time cat 2 was clinically normal (The condition of cat 1 was improving slowly; after 11 weeks, it still exhibited mild dyspnoea following exercise. Urine specific gravity remained low in cat 1 (after discontinuation of the diuretic medication), but glucosuria and cylinduria resolved completely. Urine protein/creatinine ratio was 0.13 (reference interval 0-0.5). After 96 weeks cat 1 still had polyuria and polydipsia due to chronic renal disease with serum urea and creatinine elevated approximately twofold. Mild non-regenerative anaemia was present that was attributed to chronic renal disease. 
Table 3 Analysis of the different diets that were fed

\begin{tabular}{|c|c|c|c|c|c|c|}
\hline & $\begin{array}{l}\text { Vitamin } \mathrm{D}_{3-} \\
\text { declared* }^{*} \\
(\mathrm{IU} / \mathrm{kg})\end{array}$ & $\begin{array}{l}\text { Vitamin } D_{3^{-}} \\
\text {measured }{ }^{\star \star} \\
(\mathrm{IU} / \mathrm{kg})\end{array}$ & $\begin{array}{l}\text { Calcium- } \\
\text { declared* } \\
(\mathrm{g} / \mathrm{kg})\end{array}$ & $\begin{array}{l}\text { Calcium- } \\
\text { measured }^{* \star} \\
(\mathrm{g} / \mathrm{kg})\end{array}$ & $\begin{array}{l}\text { Phosphate- } \\
\text { declared* }^{*} \\
(\mathrm{~g} / \mathrm{kg})\end{array}$ & $\begin{array}{l}\text { Phosphate- } \\
\text { measured }^{\star *} \\
(\mathrm{~g} / \mathrm{kg})\end{array}$ \\
\hline \multirow{2}{*}{$\begin{array}{l}\text { Food 1: wet food } \\
\text { (Almo Nature Kitten } \\
\text { with chicken) }\end{array}$} & OS: 1500 & OS: 46,900 & OS: 10.5 & OS: 0.7 & OS: 7.5 & \multirow{6}{*}{$\begin{array}{l}\text { OS: } 1.9 \\
\text { DM: } 8.2\end{array}$} \\
\hline & DM: 6466 & DM: 202,155 & DM: 45 & DM: 3.0 & DM: 32 & \\
\hline \multirow{2}{*}{$\begin{array}{l}\text { Food 2: dry food } \\
\text { (Royal Canin Feline } \\
\text { Kitten 36) }\end{array}$} & OS: 700 & \multirow{4}{*}{$\begin{array}{l}\text { OS: } 978 \\
\text { DM: } 1052\end{array}$} & \multirow{2}{*}{\multicolumn{2}{|c|}{$\begin{array}{l}\text { OS: } 11 \\
\text { DM: } 11.8\end{array}$}} & \multirow{2}{*}{$\begin{array}{l}\text { OS: } 9.6 \\
\text { DM: } 10.3\end{array}$} & \\
\hline & DM: 753 & & & & & \\
\hline \multirow{2}{*}{$\begin{array}{l}\text { Renal diet: wet food } \\
\text { (Hill's Feline k/d) }\end{array}$} & OS: 235 & & \multirow{2}{*}{\multicolumn{2}{|c|}{$\begin{array}{l}\text { OS: } 1.4 \\
\text { DM: } 6.3\end{array}$}} & \multirow{2}{*}{$\begin{array}{l}\text { OS: } 0.9 \\
\text { DM: } 3.8\end{array}$} & \\
\hline & DM: 1046 & & & & & \\
\hline
\end{tabular}

*Stated label amount

${ }^{* *}$ Actual content that was measured in a certified laboratory

$\mathrm{OS}=$ original substance (wet weight, as fed); DM = dry matter

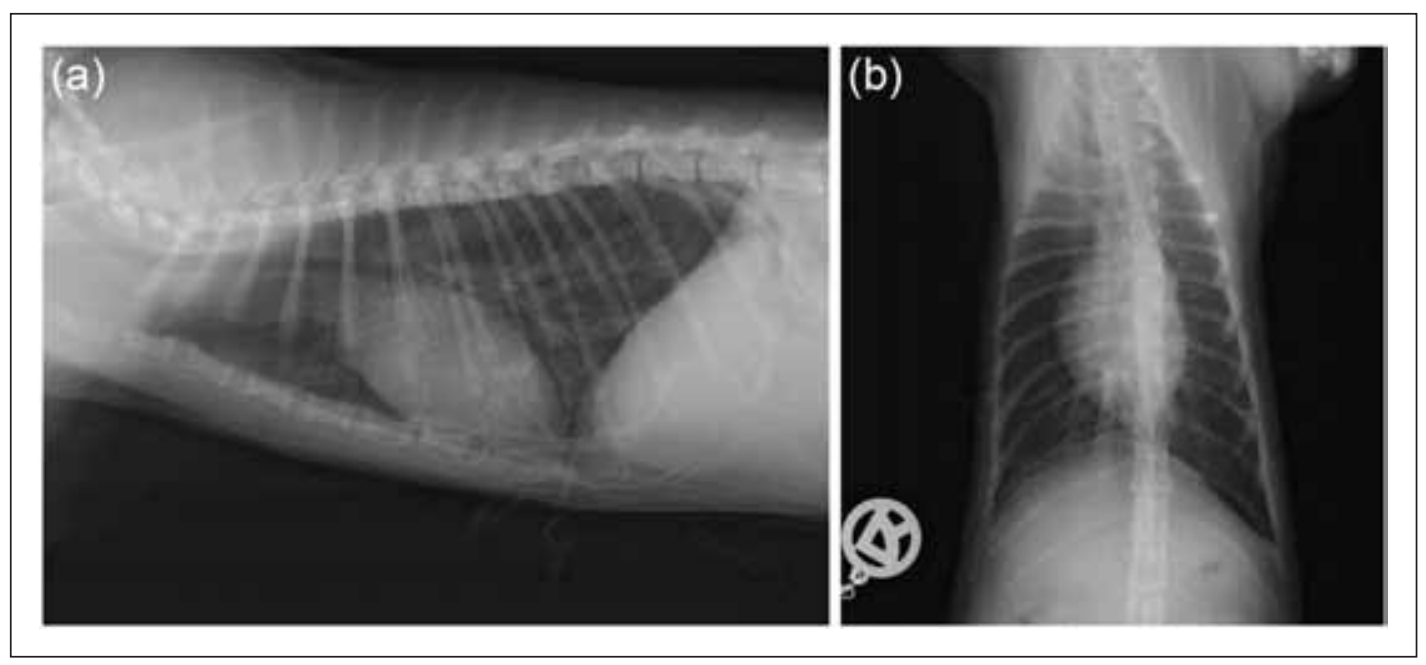

Figure 2 Thorax, right lateral (a) and dorsoventral (b) view of cat 1 after (84 days) 12 weeks. An improved generalised unstructured bronchointerstitial pattern was observed. The bronchial mineralisation appeared less conspicuous and the mineral opacity line superimposed on the cardiac silhouette showed larger gaps than in the first set of radiographs

Measurement of serum vitamin $\mathrm{D}_{3}$ metabolites was repeated in cat 1 after 11 weeks. The level of $25(\mathrm{OH}) \mathrm{D}_{3}$ had returned to within the reference interval, whereas $1.25(\mathrm{OH})_{2} \mathrm{D}_{3}$, despite a distinct decrease, was still markedly elevated (Tables 1 and 2).

The radiographic pulmonary changes were re-evaluated after 11 weeks in cat 1 and an improved generalised unstructured bronchointerstitial pattern was observed. The bronchial mineralisation appeared less conspicuous than in the first set of radiographs (Figure 2).

\section{Discussion}

Diet and skin are sources of vitamin $\mathrm{D}_{3}$. In dogs and cats the synthesis of vitamin $\mathrm{D}_{3}$ in the skin is inadequate and much lower than in other mammals. Therefore, vitamin D supply depends exclusively on dietary vitamin $\mathrm{D}_{3} \cdot{ }^{6,7}$ Vitamin $\mathrm{D}_{3}$ is converted in the liver to $25(\mathrm{OH}) \mathrm{D}_{3}$, then hydroxylated, primarily in the kidney, to $1,25(\mathrm{OH})_{2} \mathrm{D}_{3}$ by the enzyme $1 \alpha$-hydroxylase and, finally, to 24,25 -dihydroxycholecalciferol $\left[24,25(\mathrm{OH})_{2} \mathrm{D}_{3}\right]$ with the aid of 24-hydroxylase..$^{8-11}$ One study in the USA demonstrated that $21 / 49$ canned cat foods exceeded $7500 \mathrm{IU} / \mathrm{kg}$ of cholecalciferol, which corresponds to 30 times the vitamin D requirement in kittens. ${ }^{12,13}$ Mostly, the high vitamin D levels were considered to be caused by the use of raw food materials rich in vitamin $\mathrm{D}$, for example oily marine fish, rather than the over-zealous supplementation of vitamins. ${ }^{12}$ The minimum requirement of $250 \mathrm{IU} / \mathrm{kg}$ (dry matter) of cholecalciferol is considered safe if the calcium and phosphate concentrations are 12 and $8 \mathrm{~g} / \mathrm{kg}$ respectively. ${ }^{8}$ However, this might not necessarily reflect the optimum vitamin $\mathrm{D}$ allowance and may be different for other types of cat foods with different calcium and phosphate levels. ${ }^{14}$

In addition, higher levels do not necessarily represent toxic levels. The National Research Council (NRC) 2006 
Table 4 Composition of food 1 (as indicated by the manufacturer)

\begin{tabular}{ll|}
\hline Ingredients & Percentage (\%) \\
\hline Chicken meat & 75 \\
Rice & 9 \\
Cheese & 7.5 \\
Sunflower oil & 4.5 \\
Chicken liver & 1.5 \\
Egg & 1.5 \\
\hline
\end{tabular}

recommendations allow a minimum of $224 \mathrm{IU} / \mathrm{kg}(5.6$ $\mu \mathrm{g} / \mathrm{kg})$ and a maximum of $30,000 \mathrm{IU} / \mathrm{kg}(750 \mu \mathrm{g} / \mathrm{kg})$ in the dry matter of cholecalciferol for kittens after weaning. ${ }^{15}$ The levels of vitamin $\mathrm{D}$ in cats foods should be between the minimum allowance and the safe upper limit, which was established by Sih et al. ${ }^{4}$

While the dry food (food 2) in this case series contained $978 \mathrm{IU}$ vitamin $\mathrm{D}_{3} / \mathrm{kg}$ (original substance), the wet food that was predominantly given (food 1) had a vitamin $\mathrm{D}_{3}$ content of $46,900 \mathrm{IU} / \mathrm{kg}$ (original substance). Both were measured in a certified laboratory (LUFA-ITL $\mathrm{GmbH}$, Agrolab Laborgruppe, Kiel, Germany). Relating to the dry matter, this food (food 1: $23.2 \%$ dry matter) contained 202,155 IU vitamin $\mathrm{D}_{3} / \mathrm{kg}$, whereas the second food (food 2: 93\% dry matter) contained 1052 IU vitamin $\mathrm{D}_{3} / \mathrm{kg}$. The calcium and phosphate contents of food 1 were measured in a certified laboratory (Department of Nutrition and Dietetics, Ludwig Maximilian University Munich, Germany). The calcium content was $0.7 \mathrm{~g} / \mathrm{kg}$ (original substance) respectively $3.0 \mathrm{~g} / \mathrm{kg}$ dry matter. Phosphorus content was $1.9 \mathrm{~g} / \mathrm{kg}$ (original substance) respectively $8.2 \mathrm{~g} / \mathrm{kg}$ dry matter (Table 3 ). The calcium:phosphorus (Ca:P) ratio was 0.4 .

The company that produced food 1 states that no vitamin $\mathrm{D}$ is added and that the entire vitamin D content derives from natural ingredients (Table 4). However, it is unrealistic that the declared vitamin D content would be achieved solely by those ingredients. According to the European Union regulations the amount of additives that is declared is the added amount, not the total amount present in the food. If vitamin D is added as an additive the total amount of vitamin $\mathrm{D}$ in the product should not be higher than $2275.7 \mathrm{IU} / \mathrm{kg}$ dry matter. ${ }^{16-18}$ Obviously, food 1 had been enriched with excessive amounts of vitamin $\mathrm{D}$. The product therefore contained an illegal level of vitamin D.

Calculation of diet revealed that cat 1 received 10,332 IU cholecalciferol, $374 \mathrm{mg}$ calcium and $610 \mathrm{mg}$ phosphate per day. According to the NRC, the safe upper limit in the diet for cholcalciferol is $30,000 \mathrm{IU} / \mathrm{kg}$ (dry matter); 7520 IU/1000 kcal metabolisable energy (ME) for kittens after weaning. ${ }^{15}$ However, cat 1 received 29,436 IU cholecalciferol/1000 kcal ME.
The recommended calcium allowance by the NRC is $8.0 \mathrm{~g}$ calcium $/ \mathrm{kg}$ dry matter. Though calcium requirements were not met owing to the low calcium content of food 1 and could not be balanced by the small amounts of food 2, and the Ca:P ratio of the diet was inverse, vitamin $\mathrm{D}$ intoxication was possible. ${ }^{14} \mathrm{~A}$ Ca:P ratio in the range of 1.31:2.61 is reported to be adequate for growing kittens. ${ }^{15,19}$

In a case series of food-induced hypervitaminosis D from Japan, the vitamin $\mathrm{D}_{3}$ contents of these diets were reported to be $63,700 \mathrm{IU} / \mathrm{kg}$ (original substance). One more recent report from the UK describes two dogs with hypervitaminosis $\mathrm{D}$ that were fed the same food which was over supplemented with vitamin D. 3,20

Concentration of plasma $25(\mathrm{OH}) \mathrm{D}_{3}$ is generally used as an index of the vitamin D status, and elevated concentrations indicate hypervitaminosis D. Plasma concentration of $25(\mathrm{OH}) \mathrm{D}_{3}$ is linearly related to dietary intake of vitamin $\mathrm{D}_{3}$. Therefore, circulating levels of $25(\mathrm{OH}) \mathrm{D}_{3}$ could be used as a bioassay for the vitamin $\mathrm{D}$ content in the diet. ${ }^{8}$

Calcitriol is regarded to be the most active vitamin $\mathrm{D}_{3}$ metabolite with regard to calcium metabolism. Calcitriol has a high affinity for the vitamin D receptor (VDR) and a low affinity for the transport protein Vitamin D binding protein (DBP). Binding to the VDR in the nucleus of target cells causes exaggerated gene expression. Binding to DBP increases functional half-life and protects against vitamin $\mathrm{D}$ intoxication. Free vitamin $\mathrm{D}$ metabolites are functional in vivo. High $25(\mathrm{OH}) \mathrm{D}_{3}$ concentrations will cause excessive synthesis of $1,25(\mathrm{OH})_{2} \mathrm{D}_{3}$, but also, together with vitamin $\mathrm{D}$ and its other metabolites, exceed the binding capacity of DBP, thereby increasing the amount of free $1,25(\mathrm{OH})_{2} \mathrm{D}_{3}$ that is accessible to target cells. ${ }^{10,11}$ This may result in increased biological activity of $1,25(\mathrm{OH})_{2} \mathrm{D}_{3}$ without a concomitant increase in the total plasma. ${ }^{9,21}$ Vitamin D intoxication will develop eventually if the input of vitamin D or its metabolites exceed the adaptive capacity of the body to eliminate them. ${ }^{9-11}$

Cats 1 and 2 had severely increased plasma $25(\mathrm{OH}) \mathrm{D}_{3}$ and $1,25(\mathrm{OH})_{2} \mathrm{D}_{3}$ levels, supporting the diagnosis of hypervitaminosis D. Although the increased $1,25(\mathrm{OH})_{2} \mathrm{D}_{3}$ concentration is always observed, as mentioned earlier, a decreased clearance rate could explain this finding. It is also possible that the food was also over-fortified with $1,25(\mathrm{OH})_{2} \mathrm{D}_{3}$. Increased plasma $25(\mathrm{OH}) \mathrm{D}_{3}$ and $1,25(\mathrm{OH})_{2} \mathrm{D}_{3}$ levels were also found in two dogs with hypervitaminosis $\mathrm{D}$ caused by consumption of commercial dog food. ${ }^{20}$

Clinical signs, results of bloodwork and thoracic radiographs of cats in this cases series match those of previously documented cases of hypervitaminosis D. ${ }^{1-4}$ Although alkalosis is documented frequently in affected cats owing to volume depletion and an increase in 
bicarbonate reabsorption by the kidneys, cat 1 had a mixed acidosis and cat 2 had no acid-base disturbance. Changes in cat 1 most likely reflect net retention of hydrogen ions due to renal disease and possible restrictive ventilator defects due to calcifications of the lung leading to metabolic and respiratory acidosis. Although pulmonary changes consistent with mineralisation were present radiographically in two cases (cats 1 and 2), clinical and radiographic improvement was observed. To our knowledge this has not been reported before. The very low calcium content of food 1 might have prevented more severe and irreversible calcification of soft tissues, and may have reduced the toxicity of vitamin D. ${ }^{14}$

There is little published data on how cats affected by hypervitaminosis D should be treated. Cats 1 and 2 were treated initially with isotonic saline to increase calciuresis, and oral sucralfate to reduce intestinal calcium and phosphorus absorption. Terbutaline was added to achieve bronchodilation in cat 1 , which showed dyspnoea. Furosemide was added to the treatment after rehydration was achieved. After all diagnostics had been performed, prednisolone was given in tapering doses for a total of 10 days as isotonic saline and furosemide were insufficient to resolve hypercalcaemia. It resolved on day 14 in both cats. Therefore, it can be concluded that isotonic saline, sucralfate, furosemide and prednisolone successfully treated hypercalcaemia in cats 1 and 2, and can be recommended to treat vitamin D intoxication in cats. Use of bisphosphonates ${ }^{22,23}$ was discussed with the owner; however, oral alendronate (Fosamax; MSD) was not given because it was impossible to pill cats 1 and 2 and side effects, such as oesophageal ulceration, were feared.

\section{Conclusions}

Hypercalcaemia can persist for several weeks despite the withdrawal of the over-fortified diet. Its main transported metabolite, $25(\mathrm{OH}) \mathrm{D}_{3}$, shows a half-life of approximately 15 days in studies of experimental hypervitaminosis in dogs, whereas the hormone $1,25(\mathrm{OH})_{2} \mathrm{D}_{3}$ has a half-life of approximately $15 \mathrm{~h} \cdot{ }^{11}$ In cat 1 , calcidiol had returned to a concentration within the reference interval 11 weeks after treatment was started. Also, $1,25(\mathrm{OH})_{2} \mathrm{D}_{3}$ decreased but was still elevated after 11 weeks. The presence of renal failure in cat 1 might have impaired 24-hydroxylation and renal clearance of metabolites. In the two reported dogs with hypervitaminosis $\mathrm{D}$ caused by ingestion of commercial dog food $1,25(\mathrm{OH})_{2} \mathrm{D}_{3}$ normalised in one dog on day 14 and in the other after 37 days, which also indicates long half-lives. ${ }^{20}$ After accumulation in fat tissue, $25(\mathrm{OH}) \mathrm{D}_{3}$ is further metabolised slowly.

The reported cases indicate that excessive vitamin $\mathrm{D}_{3^{-}}$ containing commercially available cat food poses a great hazard to cats.
This is the first report in which treatment and longterm outcome of hypervitaminosis D, including improvement of radiologic pulmonary abnormalities, could be documented.

Funding The authors received no specific grant from any funding agency in the public, commercial or not-for-profit sectors for the preparation of this case series.

Conflict of interest The authors do not have any potential conflicts of interest to declare.

\section{References}

1 Moore FM, Kudisch M, Richter K and Faggella A. Hypercalcemia associtated with rodenticide poisoning in three cats. J Am Vet Med Assoc 1988; 193: 1099-1100.

2 Peterson EN, Kirby R, Sommer M and Bovee KC. Cholecalciferol rodenticide intoxication in a cat. I Am Vet Med Assoc 1991; 199: 904-906.

3 Morita T, Awakura T, Shimada A, Umemura T, Nagai T and Haruna A. Vitamin D toxicosis in cats: natural outbreak and experimental study. J Vet Med Sci 1995; 57: 831837.

4 Sih TR, Morris JG and Hickman MA. Chronic ingestion of high concentrations of cholecalciferol in cats. Am J Vet Res 2001; 62: 1500-1506.

5 Park IC, Lee HS, Kim JT, Nam SJ, Choi R, Oh KS, et al. Ultrasonographic evaluation of renal dimension and resistive index in clinically healthy Korean domestic short-hair cats. J Vet Sci 2008; 9: 415-419.

6 How KL, Hazewinkel HA and Mol JA. Photosynthesis of vitamin $\mathrm{D}_{3}$ in cats. Vet Rec 1994; 134: 384.

7 How KL, Hazewinkel HA and Mol JA. Dietary vitamin D dependence of cat and dog due to inadequate cutaneous synthesis of vitamin D. Gen Comp Endocrinol 1994; 96: 12-18.

8 Morris JG, Earle KE and Anderson PA. Plasma 25-hydroxyvitamin $D$ in growing kittens is related to dietary intake of cholecalciferol. J Nutr 1999; 129: 909-912.

9 Tryfonidou MA, Oosterlaken-Dijksterhuis MA, Mol JA, van den Ingh TS, van den Brom WE and Hazewinkel HA. 24-Hydroxylase: potential key regulator in hypervitaminosis $\mathbf{D}_{3}$ in growing dogs. Am J Physiol Endocrinol Metab 2003; 284: 505-513.

10 Vieth R. The mechanisms of vitamin D toxicity. Bone Miner 1990; 11: 267-272.

11 Jones G. Pharmacokinetics of vitamin D toxicity. Am J Clin Nutr 2008; 88: 582-586.

12 Morris JG. Vitamin synthesis by kittens. Vet Clin Nutr 1996; 3: 88-92.

13 Morris JG and Earle KE. Vitamin D and calcium requirements of kittens. Vet Clin Nutr 1996; 3: 93-96.

14 Vieth R, Fraser D and Kooh SW. Low dietary calcium reduces 25-hydroxycholecalciferol in plasma of rats. J Nutr 1987; 117: 914-918.

15 National Research Council. Nutrient requirement of dogs and cats. Washington, DC: National Academy Press, 2006, pp 364-365.

16 Commission Regulation (EC) No 767/2009 of the European Parliament and of the Council of 13 July 2009 on the placing on the market and use of feed OJEC 1.9.2009 L229/1-28. 
17 European Union. Regulation (EC) No 1831/2003 of the European Parliament and of the Council of 22 September 2003 on additives for use in animal nutrition. Official Journal of the European Union 18.10.2003 L268/29-43.

18 European Union. 2004/C 50/01 List of the authorised additives in feedingstuffs ( $\left.{ }^{1}\right)$ published in application of Articla 9t (b) of Council Directive 70/524/EEC concerning additives in feedingstuffs. Official Journal of the European Union 25.2.2004 50/1-144.

19 Morris JG and Earle KE. Growing kittens require less dietary calcium than current allowances. J Nutr 1999; 129: 1698-1704.

20 Mellanby RJ, Mee AP, Berry JL and Herrtage ME. Hypercalcaemia in two dogs caused by excessive dietary supplementation of vitamin D. J Small Anim Pract 2005; 46: 334-338.

21 Deluca HF, Prahl JM and Plum LA. 1,25-Dihydroxyvitamin $\mathrm{D}$ is not responsible for toxicity caused by vitamin $\mathrm{D}$ or 25-hydroxyvitamin D. Arch Biochem Biophys 2011; 505: 226-230.

22 Price PA, Buckley JR and Williamson MK. The amino bisphosphonate ibandronate prevents vitamin $\mathrm{D}$ toxicity and inhibits vitamin D-induced calcification of arteries, cartilage, lungs and kidneys in rats. J Nutr 2001; 131: 29102915.

23 Rumbeiha WK, Kruger JM, Fitzgerald SF, Nachreiner RF, Kaneene JB, Braselton WE, et al. Use of pamidronate to reverse vitamin $\mathrm{D}_{3}$-induced toxicosis in dogs. Am J Vet Res 1999; 60: 1092-1097. 